\title{
LA ENCRIPTACIÓN DEL DUELO EN FORMAS DE VOLVER A CASA DE ALEJANDRO ZAMBRA, FUENZALIDA DE NONA FERNÁNDEZ Y LA EDAD DEL PERRO DE LEONARDO SANHUEZA
}

\author{
THE ENCRYPTION OF MOURNING IN FORMAS DE VOLVER \\ A CASA BY ALEJANDRO ZAMBRA, FUENZALIDA BY NONA \\ FERNÁNDEZ AND LA EDAD DEL PERRO BY LEONARDO \\ SANHUEZA
}

\section{BERNARDO PATRICIO ROCCO NÚÑEZ*}

Resumen: El artículo estudia las novelas Formas de volver a casa (2011) de Alejandro Zambra, Fuenzalida (2012) de Nona Fernández y La edad del perro (2014) de Leonardo Sanhueza. Las narraciones exhiben una memoria inmanente de lo cotidiano que es insinuada por subjetividades dolientes que se vuelcan hacia el pasado traumático de la dictadura cívico-militar chilena. De esta manera, se plantea que la representación de esa experiencia de infancia y adolescencia en dictadura deviene en una constante elaboración escritural de un estado de melancolía que persiste en el trabajo de duelo: su encriptación.

Palabras Clave: Dictadura chilena, trauma, duelo, melancolía, encriptación.

Aвstract: This article examines the novels Formas de volver a casa (2011) by Alejandro Zambra, Fuenzalida (2012) by Nona Fernández and La edad del perro (2014) by Leonardo Sanhueza. These novels display the exercise of an immanent memory of daily life intimated by a mournful narrative subject who, from a neoliberal present, turns to the traumatic past of Chile's civic-military dictatorship. This article argues that the novels' representation of early childhood and adolescence during the dictatorship unfolds in a persistent scriptural elaboration, or encryption, of a state of melancholy perpetuated by the work of mourning.

KEYwORDs: Chilean dictatorship, trauma, mourning, melancholy, encryption.

Recibido: 03.04.18. Aceptado: 05. 04.19.

* Doctor en Literatura Chilena e Hispanoamericana, Universidad de Chile. Profesor de la Universidad Tecnológica de Chile INACAP. Correo electrónico: stereohead73@gmail.com 


\section{INTRODUCCIÓN}

T As novelas Formas de volver a casa (2011) de Alejandro Zambra, LFuenzalida (2012) de Nona Fernández y La edad del perro (2014) de Leonardo Sanhueza manifiestan la puesta en ejercicio de una memoria inmanente de la cotidianidad aludida por una subjetividad narrativa doliente que, desde un presente neoliberal, se vuelca hacia el pasado traumático, específicamente al período de la infancia y la adolescencia durante la dictadura militar chilena. La memoria en el corpus de estudio se relaciona específicamente con un pasado deshistorizado donde un cotidiano constituido por un ahí manifiesta la diseminación de un yo que rememora una época (Rojas, 2015, pp. 238-253). Además, la figura de la memoria concentra la tensión irresuelta entre recuerdo y olvido del duelo histórico que no ha podido asimilar el sentido de la pérdida (Richard, 1994, p. 13). En otras palabras, la reactualización del pasado a través del esfuerzo afectivo y reflexivo de quienes no padecieron directamente el evento traumático, conocido también como postmemoria (Hirsch, 1999, p. 8), corrobora las ideas sobre el retorno de lo reprimido, los efectos del trauma y la latencia (Freud, 1967, p. 129). En este sentido, el presente artículo plantea que la representación de la experiencia de la dictadura, caracterizada en el corpus por un persistente impulso nostálgico de una autoconciencia biográfica doliente, deviene en la reelaboración escritural de un permanente estado de melancolía que perpetúa el trabajo de duelo: su encriptación.

Para Cristián Montes la "persistencia del imaginario dictatorial" (2018, p. 279) en la producción narrativa de los hijos, se explicaría por "las formas en que esta textualidad ha procesado la experiencia colectiva del duelo y los efectos del trauma generado por la debacle simbólica que significó el golpe militar y los años de represión en Chile" (p. 280). Es decir, el funcionamiento del "ideologema de la dictadura" (p. 280) como imaginario social permitiría comprender la fidelidad al trauma y la continuación del proceso de duelo (pp. 280-281). Una explicación similar esgrime María Angélica Franken para referirse a los "imaginarios de formación" de los hijos (2017, p. 187) cuando afirma que la narrativa de estos escritores lo que lleva a cabo "es la actualización del origen traumático - golpe militar- en un conflicto particular que se traduce en la tensión y negociación con la serie de imaginarios formativos de la dictadura y la posdictadura que siguen sintiéndose y transformándose en el presente" (p. 189). Precisamente lo que Nelly Richard (2007) percibe sobre el pensamiento de la postdictadura donde "cunde la melancolía como estado aflictivo de irresolución del 
duelo" (p. 170). En otras palabras, para Richard "(el golpe como trauma, el duelo como pérdida de objeto y la melancolía como suspensión irresuelta del duelo) son las figuras que, extraídas del repertorio freudiano, le prestaron su tonalidad afectiva al pensamiento de la postdictadura" (p. 171). Según Tomás Moulian (1997), para comprender la actualidad chilena es preciso establecer el vínculo histórico que la postdictadura sostiene con la dictadura. Este vínculo es comprendido por Moulian como la culminación exitosa del "transformismo" y es definido como el

largo proceso de preparación, durante la dictadura, de una salida de la dictadura, destinada a permitir la continuidad de sus estructuras básicas bajo otros ropajes políticos, las vestimentas democráticas. El objetivo es el "gatopardismo", cambiar para permanecer. Llamo "transformismo" a las operaciones que en el Chile Actual se realizan para asegurar la reproducción de la "infraestructura" creada durante la dictadura, despojada de las molestas formas, de las brutales y de las desnudas "superestructuras" de entonces. El "transformismo" consiste en una alucinante operación de perpetuación que se realizó a través del cambio del Estado. (p. 145)

En consecuencia, la narrativa de Nona Fernández (1971), Leonardo Sanhueza, (1974) y Alejandro Zambra (1975) ${ }^{1}$, lo que hace es contribuir a la persistencia del imaginario dictatorial de formación mediante la reactualización del estado aflictivo de un duelo incompleto: el vínculo histórico. No obstante, todo indica que en la persistencia del anhelo melancólico con la cosa perdida o "estoicismo" (Álvarez, 2012, p. 7) converge también un proceso denominado "encriptación", en el cual el objeto traumático permanece incubado dentro del yo como un cuerpo extraño, innombrable, excepto a través de sinónimos parciales (Abraham y Torok, 1994, pp. 125-138) y que excede con creces la estricta persistencia del imaginario dictatorial de formación desarrollado por esta narrativa.

Como se estudiará, la condición espectral de elementos del pasado que siguen presentes como latencias en los relatos de estos autores determina que la narrativa de esta generación actúe como "phantom carrier" (Berthin, 2010, p. 4) de una historia que los acecha de forma obsesiva. Específicamente, el de una Historia desintegrada que deviene en petit récit (Lyotard,

\footnotetext{
${ }^{1}$ Así como la de otros escritores coetáneos: Alejandra Costamagna, Andrea Maturana, Rafael Gumucio, Andrea Jeftanovic, Álvaro Bisama, AliaTrabucco Zerán, Gonzalo Eltesch, Lina Meruane, Daniel Campusano, Diego Zúñiga, Daniel Villalobos, entre muchos otros.
} 
1984, p. 60) y caracterizado por un "repliegue minimalista, contraépico y antitremendista" (Rojo, 2016, p. 127), alejado de los grandes relatos históricos. Es decir, pequeños relatos de infancia y adolescencia que acentúan la "evocación melancólica" de los narradores (Opazo, 2009, p. 93). De esta manera, el análisis propuesto se focalizará en tres ejes fundamentales: melancolía-duelo; trauma heredado-directo; e incorporación-encriptación.

\section{MELANCOLÍA Y DUELO}

En Formas de volver a casa de Alejandro Zambra, si bien se recuerda la cotidianidad de la dictadura desde la perspectiva de un niño de nueve años, el relato expone también su propia lógica interna, evidenciando las dudas y reflexiones del escritor sobre las relaciones entre la realidad nacional pasada y presente. A partir de la autoconciencia biográfica, expresada mediante el diario y la nostalgia de la infancia, surge el sentimiento melancólico sobre la experiencia del duelo de una generación que intenta comprender lo que sucedía en esos años, pero que asimismo anhela crear su propio relato que haga frente a las versiones oficiales de quienes participaron, aunque indirectamente, de la dictadura:

La novela es la novela de los padres, pensé entonces, pienso ahora. Crecimos creyendo eso, que la novela era de los padres. Maldiciéndolos y también refugiándonos, aliviados, en esa penumbra. Mientras los adultos mataban o eran muertos, nosotros hacíamos dibujos en un rincón. Mientras el país se caía a pedazos nosotros aprendíamos a hablar, a caminar, a doblar las servilletas en forma de barcos, de aviones. Mientras la novela sucedía, nosotros jugábamos a escondernos, a desaparecer. (2011, pp. 56-57)

La autoconciencia biográfica del narrador irrumpe en la materia novelesca, esta vez, con el propósito de hacer una analogía literaria, la de la novela, entre la generación de sus padres y la de quienes no experimentaron directamente las consecuencias de la dictadura. El aspecto melancólico está dado por la modulación de una mirada triste y nostálgica que, desde un presente neoliberal de postdictadura, reflexiona sobre dos realidades que coexistieron en una época, y que ahora emergen convergiendo en el trabajo de duelo o el momento en el cual se asignan las responsabilidades y culpas producidas por el evento traumático: el golpe de Estado. 
La íntima relación de convergencia que el narrador de Formas de volver a casa establece entre melancolía y duelo, a partir del evento traumático del golpe de estado, lo que es aplicable también a los otros narradores del corpus, es algo que se ajusta a lo que Freud entiende por ambos conceptos: "Por tanto, la melancolía toma prestados una parte de sus caracteres al duelo, y la otra parte a la regresión desde la elección narcisista de objeto hasta el narcisismo. Por un lado, como el duelo, es reacción frente a la pérdida real del objeto de amor, pero además depende de una condición que falta al duelo normal o lo convierte, toda vez que se presenta, en un duelo patológico" (1992, p. 248).

En este sentido, si el duelo en las novelas es la respuesta a la muerte de un ser querido (la pérdida del objeto o la inocencia), entonces la melancolía es una respuesta -dado que nadie ha muerto, no hay objeto perdido-, en la cual el ego mismo se convierte en el objeto perdido: la autoconciencia biográfica doliente.

Con respecto a Fuenzalida de Nona Fernández, la novela se desarrolla en torno a la constante disputa que la protagonista lleva a cabo en contra de una memoria fragmentada y oscura sobre la dictadura chilena. En este contexto, la protagonista se ve enfrentada al recuerdo de su padre, Ernesto Fuenzalida, a quien dejó de ver cuando era una niña. Si bien la novela despliega otros dos relatos intercalados de carácter más bien detectivescos, lo relevante de la narración reside en cómo la protagonista intenta reconstruir los pequeños fragmentos de la cotidianidad con su progenitor y de paso también rehacer obsesivamente algunos hechos violentos de la época que le permitan continuar conservando en su memoria nostálgica los retazos de lo que fue la figura de un padre misterioso:

Este recuerdo ocurre entre ruedas que giran (...) No tengo fotografías de esta escena, pero voy a apostar a que es real. Hay ciertas cosas que me avalan (...) sobre todo el recuerdo de una noticia escuchada en la radio (...) un hecho verídico que está registrado mínimamente en la prensa de la época y en el recuerdo de algunas personas (...) El locutor de la radio narra un acontecimiento macabro (...) un hombre se habría quemado a lo bonzo frente a la Catedral de Concepción. Sus hijos se encontrarían detenidos hace un par de días por organismos de seguridad y, exigiendo información de forma desesperada, el padre habría tomado la radical decisión (...) Cuando Fuenzalida y este recuerdo ya se habían borroneado, intenté encontrar información sobre lo que escuché esa tarde en la radio (...) pero no di con mucho. Era como si alguien hubiera tijereteado la escena (...) Desde ese momento la idea de conocer más sobre ella se volvió obsesiva. (2012, pp. 143-148) 
A diferencia de la novela de Zambra, la narradora se centra aquí en la relación casi inexistente entre padre e hija, intentado reconstruirla a partir de los recuerdos reales o ficticios de una realidad fragmentada. Es precisamente en el intento de la autoconciencia biográfica de la guionista donde irrumpe el impulso nostálgico de carácter doloroso y obsesivo por dar sentido a la historia de un acontecimiento macabro ocurrido durante la dictadura y que la persigue hasta la actualidad.

Finalmente, La edad del perro de Leonardo Sanhueza adquiere su densidad biográfica mediante la autoconciencia infantil de un niño llamado también Leonardo, quien relata, desde el techo de su casa, su vida entre los nueve y diez años en Temuco, en un barrio de clase media, junto a su madre y abuelos; pero también bajo la sombra de su padre, mecánico de la Fuerza Aérea -borracho empedernido- que lo abandona a muy temprana edad. La rutina diaria de Leonardo se perfila hacia una realidad donde impera el sentimiento de aburrimiento absoluto, donde la única opción de vida consiste en el sometimiento a las normas escolares o familiares que impone su abuelo, un ex carabinero, que tiene una imagen del dictador en su dormitorio y que detesta a los izquierdistas. La novela en su atmósfera de tristeza se corresponde con el persistente impulso nostálgico de un sujeto melancólico:

Luego volvimos a Temuco, afines del setentaicinco, cuando él fue trasladado a la base Maquehue. El traslado fue una buena noticia para la joven familia. Aunque mi mamá se había adaptado bien a la vida en Santiago, después del golpe había empezado a sentir una creciente nostalgia por el sur. De modo que volver a la Frontera era una especie de anhelada repatriación, un premio inesperado. El sur había sido el lugar de todos durante numerosas generaciones. A nuestra casa nomás llegábamos. Y fue entonces, cuando yo tenía dos años, que el cuento de hadas se acabó, no como se acaban los cuentos, con colorín colorado y campanitas, sino como se acaba un libro al que le han arrancado la mejor parte y el final. (2014, p. 59)

Al igual que la novela de Zambra, el narrador de La edad del perro hace uso aquí de una analogía literaria, la del cuento, para referir el final abrupto a la inocencia durante la dictadura. Nuevamente, la persistencia del impulso nostálgico del narrador describe los acontecimientos familiares enmarcados por las circunstancias históricas de la década de los setenta. 


\section{TRAUMA HEREDADO VERSUS DIRECTO}

Los relatos de Zambra, Fernández y Sanhueza abordan el trauma de los hijos de la dictadura a través de una experiencia indirecta o de segundo orden. Es decir, son relatos correspondientes a una generación que lidia con el trauma y es heredera de un trauma. Por este motivo, el proceso de duelo y encriptación opera de manera distinta, por ejemplo, al de la novela El daño (1997) o el relato "Al fondo del patio" (No decir, 2006) de Andrea Maturana, donde se aborda el trauma de la dictadura mediante una experiencia directa: el incesto y la dificultad para evocar los recuerdos y las palabras. En este sentido, los protagonistas del corpus de estudio no sufren la violencia directa y el abuso sexual presentes en la narrativa de Maturana. Como dice el narrador de Formas de volver a casa: "Soy el hijo de una familia sin muertos, pensé mientras mis compañeros contaban sus historias de infancia" (p. 105). No obstante, esto no impide que el trabajo de duelo y encriptación del trauma heredado de la dictadura no emerja textualmente en las novelas. En efecto, los narradores repiten mediante la reelaboración de hechos traumáticos situaciones parcialmente silenciadas y no elaboradas en primera instancia durante la infancia y la adolescencia.

En el contexto del terremoto de 1985, el narrador de Formas de volver a casa reflexiona sobre la época de la dictadura:

Ahora no entiendo bien la libertad de que entonces gozábamos. Vivíamos en una dictadura, se hablaba de crímenes y atentados, de estado de sitio y toque de queda, y sin embargo nada me impedía pasar el día vagando lejos de casa. ¿Las calles de Maipú no eran, entonces, peligrosas? De noche sí, y de día también, pero con arrogancia o con inocencia, o con una mezcla de arrogancia e inocencia, los adultos jugaban a ignorar el peligro: jugaban a pensar que el descontento era cosa de pobres y el poder asunto de ricos, y nadie era pobre ni era rico, al menos no todavía, en esas calles, entonces. (p. 23)

Desde un presente, el narrador protagonista se cuestiona la supuesta libertad existente en aquella época, y que le permitía disfrutar de la libertad de movimiento a pesar de los rumores de crímenes y atentados que circulaban. Este cuestionamiento o el despertar de la conciencia sobre las circunstancias históricas que afectan su cotidianidad infantil es lo que lleva a pensar que el trabajo de duelo persiste hasta la actualidad del personaje. De alguna manera, el cuestionamiento del protagonista alimenta, como conse- 
cuencia de la mezcla de arrogancia e inocencia estimulada por los adultos, el sentimiento de haber vivido en una burbuja que ignoraba los peligros de la época. En otras palabras, el sentimiento de culpa que siente el narrador fomenta el trauma de haber vivido bajo circunstancias privilegiadas que omitían lo que realmente sucedía en Chile. En definitiva, el trauma se reactualiza, heredándose, y de paso se encripta la culpa que el protagonista siente y que a su vez traspasa a los padres que "jugaban a ignorar el peligro", encriptándose también la responsabilidad que los adultos tuvieron en la crianza de sus hijos.

Por su parte, en Fuenzalida el trabajo de duelo y encriptación del trauma de la dictadura se desenvuelve alrededor de una imagen fotográfica encontrada por la narradora en un basurero, la de una "imagen velada de algo que ocurrió en otro momento, lejos de esta calle vacía, el destilado de una escena imposible de resucitar" (p. 17), de un hombre vestido de kimono negro. La fotografía del padre ausente aparece posteriormente ligada esta vez al itinerario que recorre la basura, funcionando como metáfora de la violencia política y de la persistencia del trauma de la dictadura y su encriptación:

De un tarro basurero se pasa a una bolsa plástica. De la bolsa plástica a un camión recolector, del camión a una estación de transferencia y de ahí a un relleno sanitario o a un vertedero. El recorrido dura lo mismo que un funeral. Los cuerpos son velados en bolsas negras, permanecen ahí durante un tiempo, en las veredas de las casas donde antes habitaron, y luego son trasladados a una gran fosa común. De ahí ya no es posible rescatar nada. La receta médica (...) la fotografía añeja del papá.Todo aquello que va a dar al mar de la mugre se mantiene flotando allí, naufraga sin posibilidad de que la corriente lo devuelva (...). Una fotografía que aún no ha sido tomada. En ella Fuenzalida y yo posamos juntos para la cámara. Una escena (...) que ya no existe o que quizá nunca existió, pero que está ahí, molestando (...). Continuamente creo tenerla en la punta de la lengua, al filo de la memoria (...). Tanto tiempo esperando este momento y todavía no estoy preparada. Nunca lo estaré. Siento que es demasiado temprano para que se lleven mi basura. Vuelvo a tener doce años en el frontis de mi casa. (pp. 69-70)

La recurrencia de la metáfora de la fotografía encontrada en un basurero actúa como un relato superpuesto y siniestro sobre los detenidos desaparecidos en dictadura. Pero también resalta el sentimiento de duelo que vive la protagonista: la ausente presencia de un padre casi desconocido y el estado de coma en que se encuentra su hijo Cosme. De cierto modo, el referente semántico de la imagen estalla con el uso metonímico intensivo de 
un lenguaje funerario, donde la bolsa plástica alude a la mortaja, el camión recolector a la carroza fúnebre, la estación de transferencia a la morgue y el relleno sanitario al cementerio. Sin embargo, es la escena de la fotografía con el padre lo que reactualiza el trauma de la protagonista, encriptándose en el momento en que la imagen familiar difuminada aparece molestándola como el "fantasma que vive en un pasado confuso, penando a veces en los escasos recuerdos" que ella tiene y que "no puede ser enterrado" (p. 165). El duelo como "al filo de la memoria" continúa y se extiende hasta la actualidad de la protagonista, quien confiesa además que no está preparada todavía para soltar el objeto perdido. De esta manera, el objeto anhelado conformado por aquella basura repleta de recuerdos de la infancia le impide concluir el duelo, prefiriendo en cambio volver a la edad de doce años o de la inocencia aún no perdida. En definitiva, a pesar de que su padre ha muerto hace ya un tiempo, la persistencia del impulso nostálgico de la autoconciencia biográfica de la protagonista termina prolongando su estado de melancolía y por extensión insistiendo en el duelo y su encriptación.

Con relación a La edad del perro, desde el inicio el motivo del padre ausente se advierte como un elemento latente y apremiante para Leonardo. El protagonista siente la necesidad de saber qué es lo que sucedió con su padre. A pesar de vivir en un ambiente doméstico donde impera el pensamiento de derecha, y en el cual prevalece el silencio y la prohibición de discutir temas políticos, Leonardo consigue, a pesar de todo, vislumbrar algunos detalles sobre su progenitor: "Ya sabía que mi papá había trabajado en la Base Manquehue, pero como hablar de mi papá es igual que hablar de política o religión, no tenía idea de que había trabajado con helicópteros" (p. 57). En esta búsqueda, el protagonista se entera de que su padre estuvo en contra del golpe militar, y que fue obligado a participar en el allanamiento de la editorial Quimantú y en el posterior asesinato de sus trabajadores. En este sentido, la triple conjunción entre el deseo de Leonardo por conocer a su padre, la violencia en torno a la editorial Quimantú y la maleta de libros roídos pertenecientes a la misma editorial, que Leonardo descubre en la bodega de su casa en Temuco, hacen que la literatura se convierta en el espacio simbólico sine qua non de la encriptación del trauma de la dictadura.

En primer lugar, la literatura y los libros corresponden al espacio donde se encripta o cifra un lenguaje con un contenido específico que a veces puede resultar peligroso. En segundo lugar, es el espacio donde el paso del tiempo manifiesta las ruinas del legado cultural de una generación de chilenos. En tercer lugar, es el espacio que le permite a Leonardo establecer re- 
laciones de correspondencia entre situaciones dramáticas no verbalizadas: "Los libros eran de la editorial Quimantú, pero no se me había ocurrido asociar eso con el golpe. Hay tantas cosas difusas, cosas que no se dicen, que solo se pueden averiguar por deducción, porque las paredes tienen oídos" (pp. 110-111). Pues como afirma Leonardo, "Quimantú pertenecía al conjunto de palabras que las paredes logran escuchar con sus oídos selectivos y que, por lo tanto conviene no decirlas" (p. 111). En consecuencia, la literatura en La edad del perro se transforma en el espacio que inscribe lo que no se puede decir, encriptando el trauma y manifestando a su vez la persistencia del impulso nostálgico de Leonardo, quien insiste mediante el trabajo de duelo, en conocer qué sucedió con su padre en aquella época.

Con respecto a la noción de encriptación en el contexto de la literatura de los hijos discutida hasta ahora, Alejandra Bottinelli (2016) provee el primer acercamiento sobre esta cuando señala a Alejandra Costamagna como la primera escritora que nombró en En voz baja (1996) la catástrofe de la dictadura, "desde un lugar de enunciación que no había existido como tal: la niñez en dictadura” (2016, p. 20):

somos los hijos de un despojo, los hijos de un robo y de una violación, de nuestros padres, nos robaron a nuestros padres [...] Fuimos hijos abandonados que aprendieron lo que querían ser en los sueños de unos padres que ya nunca volvieron a soñar. Fuimos pesadillas. Nos quedamos sin genealogía, solos y saqueados. Rompieron la continuidad, y la memoria que era de ellos no la tenemos, ésa es solo una parte muerta que uno deja dentro de otro; un hijo que no nació o que nació con sentencia de muerte. (pp. 20-21)

Si bien la incapacidad de acceder a la memoria ajena de los padres se revela, según Bottinelli, como un acto imposible para estos autores, este nuevo lugar de enunciación permitiría acceder mediante la "parte muerta que uno deja dentro de otro" a la noción de encriptación presente en el corpus.

El segundo acercamiento sobre la encriptación nace de la pregunta que Lorena Amaro Castro hace en torno a la condena que los narradores expresan hacia sus progenitores: ¿por qué los padres pudieron vivir bajo la dictadura de Pinochet sin quedar heridos? (Amaro, 2013, p. 122). Esto implicaría que si los padres no fueron heridos, serían los hijos quienes cargarían con las heridas dejadas por la dictadura. Esta idea es reafirmada por Amaro cuando señala que tanto Fernández como Zambra al retratar "aquel tiempo oscuro de la dictadura (...) produciendo una escritura (...) se apropian de algo que no les perteneció plenamente, sino que les perteneció a 'ellos', a 
los padres" (p. 125); para luego concluir retomando la metáfora del título de la novela de Zambra que "los narradores de estas historias se hallan a la intemperie, interrogándose sobre las esquirlas de la noción de familia introyectada por la dictadura a través de su propaganda ochentera. Se vuelve a casa, pero herido(a)" (p. 125).

La alusión a la idea de introyección de las heridas de la dictadura dirige el análisis hacia el tercer acercamiento sobre la encriptación que desarrolla Vania Barraza Toledo con relación a la narrativa de Andrea Maturana. Como se anticipó, al contrario de los escritores del corpus, Maturana aborda el trauma de la dictadura mediante una experiencia directa: el incesto y la problemática de recordar el pasado. En su estudio, Barraza (2011) alude a la introyección del proceso de duelo y su efecto en el cuerpo, para mencionar luego la noción de encriptación, basada en el análisis de Derrida sobre la escritura, la memoria y el concepto de fármacon:

al recuperar recuerdos traumáticos (...) éstos se transforman en memoria inscri(p)ta; es decir, pasan a ser sepultados para clausurar un proceso de duelo. Por eso, la inscripción del trauma evoca al fármacon por cuanto se trata de un proceso que cifra y 'encripta' una memoria silenciada, confinada al olvido, por lo cual, la rememoración de las protagonistas de Maturana, en lugar de des-enterrar el pasado, permite más bien velar o recubrir el dolor. Así, como un modo de ampliar la lectura derridiana sobre el texto de Platón, proponemos que el fármacon no se limita a la escritura gráfica de los recuerdos, sino al proceso mismo de recordar, de re-memorar aquello que se ha preferido callar u olvidar y que en todos los relatos de No decir, se transforman en aquel pasado culposo que regresa como fantasma una y otra vez. En consecuencia, testimoniar eventos traumáticos permite inscribirlos/encriptarlos y, al mismo tiempo, suscitaría extroyectar el duelo. El registro y re-conocimiento del trauma está asociado a asimilar la pérdida y, con eso, a olvidar (a fin de cuentas el trabajo de duelo va unido al olvido), lo cual constituye una experiencia que encadena dolor y alivio; una terapia que hiere y calma. (p. 103)

Si bien Barraza alude al proceso de encriptación observado en el corpus de análisis, para ella la obra de Maturana correspondería a lo opuesto de lo que se pretende establecer aquí. En este sentido, los personajes de Maturana sienten la necesidad de olvidar el evento traumático causado por la violencia directa. Es decir, si para Barraza la encriptación suscitaría extroyectar el duelo y, por ende, asimilar la pérdida -introyección- y olvidar la experiencia traumática, se observa en cambio lo contrario en las novelas de Zambra, 
Fernández y Sanhueza: la encriptación ${ }^{2}$ del trauma heredado que perpetúa el trabajo de duelo o su incorporación.

Para Barraza, la introyección designa un trabajo de duelo exitoso, mediante el cual el objeto perdido es absorbido y expulsado, siendo internalizado de tal modo que la libido puede depositarse en un objeto subsidiario, compensando la pérdida. Básicamente, lo expuesto por Barraza sobre la obra de Maturana. En cambio, en la incorporación, como se estudiará más adelante, el objeto traumático permanece incubado dentro del yo como un cuerpo extraño, innombrable excepto a través de sinónimos parciales. Así, en la medida en que este objeto resista y rechace la introyección ${ }^{3}$, el objeto se manifestará de manera críptica y deformada, alzando una tumba intrapsíquica en que se rehúye la pérdida y se entierra vivo el objeto perdido (Abraham y Torok, 1994, pp. 125-138).

\section{INCORPORACIÓN Y ENCRIPTACIÓN}

Idelber Avelar (2000) discute en el contexto literario latinoamericano postdictatorial la noción de cripta de Abraham y Torok. Para Avelar, la cripta en su lectura de ambos autores constituiría:

la manifestación residual de la persistencia fantásmica de un duelo irresuelto. Una teoría (...) de lo espectral y de los fantasmas (de allí su importancia para Derrida). Desde una tropología postdictatorial, la teoría de la cripta sería también componente clave de una teoría de lo alegórico (...) (de allí la constitución, visible en Benjamin, de una incipiente teoría de la cripta en el estudio de la alegoría barroca) (...) El carácter alegórico de tal espectralidad residiría en la resistencia a la figuración, propia de toda alegoría y elemento central en el proceso de incorporación (...) La melancolía emergería como una reacción a cualquier amenaza a la cripta protectora: el sujeto pasa a identificarse con el objeto perdido como forma de protegerlo de la posibilidad de ser objeto de duelo. El rechazo incorporativo al duelo se manifestaría a través de una subsunción de toda metaforicidad bajo la bruta literalidad identificada con la palabra traumática. (p. 19)

\footnotetext{
${ }^{2}$ En el caso particular del corpus, se debe precisar que la encriptación del trauma de la dictadura está relacionada más con la urgencia del yo por manifestar las deformaciones íntimas y cotidianas que el aparataje represivo de la dictadura ejerció sobre la vida privada de una generación de chilenos, que con la tenebrosa idea de tumba que Abraham y Torok desarrollan en su estudio.

${ }^{3}$ Introducir en sí la parte de sí mismo depositada en lo que se ha perdido.
} 
Si bien la representación en el corpus no está mediada por estructuras alegóricas, su constitución fragmentaria remite a un trabajo de duelo por la totalidad perdida, donde la desintegración de la Historia (dictadura) deviene en petit récit (postdictadura): la aceptación de la incorporación a través de la literalidad antitremendista (Rojo) de la palabra traumática (Avelar). En otras palabras, y siguiendo el pensamiento de Avelar desde una perspectiva distinta, la melancolía emergería como una reacción de la autoconciencia biográfica al impulso nostálgico proveniente de la cripta protectora. De esta manera, la subjetividad narrativa doliente incluida en la pérdida pasa a identificarse con una época perdida como una forma de abandonarla a la posibilidad de la persistencia del duelo: la incorporación del trauma. Como afirma Elit Ferbert (2013) con respecto a la forma de la presentación de la melancolía de Walter Benjamin:

Benjamin does not reconstruct the destroyed material, nor does he rebuild that which was lost; he retains its quality of disintegration. He therefore neither overcomes loss nor mourns that loss. Instead, his manner of working through loss involves engagement with the loss itself, with the presentation of this loss. The glue's significance in the mosaic alludes to the importance of pointing out lacunae, the spaces missing and destined to be eternally unaccounted for. (p. 66) ${ }^{4}$

En este sentido, las novelas conservan la desintegración de lo perdido mediante la presentación de la pérdida con el fin de señalar los espacios no contabilizados por la Historia. Por eso la necesidad obsesiva de los narradores chilenos por elaborar aspectos secundarios de la infancia a través de una perspectiva biográfica que dé cuenta de la densidad emocional de un pasado familiar y de la atmósfera opresiva de un país.

Con respecto a la lectura que hace Avelar sobre la obra de Abraham y Torok, el prólogo de Jacques Derrida a The Wolf Man's Magic Word: A Cryptonymy (2005) permite identificar cinco aspectos distintivos sobre el concepto de cripta visto anteriormente. Primero, señala que es el lugar de la historia de un artificio construido por la violencia. Segundo, que la incorporación interviene donde la introyección falla. Tercero, que la cripta conmemora no el objeto en sí, sino la exclusión de un deseo. Cuarto, que

\footnotetext{
4 "Benjamin no reconstruye el material destruido, ni reconstruye lo que se perdió; él conserva su cualidad de desintegración. Por lo tanto, ni supera la pérdida ni lamenta esa pérdida. En cambio, su forma de trabajar a través de la pérdida implica el compromiso con la pérdida misma, con la presentación de esta pérdida. El significado adherido al mosaico alude a la importancia de señalar lagunas, los espacios que faltan y que están destinados a ser eternamente no contabilizados". (Traducción propia)
} 
el habitante de una cripta siempre es un muerto viviente. Quinto, que el proceso de incorporación siempre conlleva la vocación nostálgica (pp. xiv$\mathrm{xxi}$.

De esta manera, cuando el narrador de Formas de volver a casa afirma que la "novela es la novela de los padres" (pp. 56-57) está aludiendo no solo a un procedimiento literario como la mise en abyme -el lugar de un artificio-, sino que también a la historia de un artificio, de un singular enclave construido por la novela -en el presente- donde el artefacto novela manifiesta la violencia del pasado dictatorial. Lo mismo ocurre con el narrador de Fernández en Fuenzalida mediante el uso intensivo a lo largo de la novela del procedimiento literario del montage cinematográfico: "No tengo fotografías de esta escena, pero voy a apostar a que es real" (p. 143), que transporta una multiplicidad tijereteada de escenas de la dictadura al presente narrativo de la protagonista. Por su parte, el narrador de La edad del perro recurre asimismo al género literario del cuento de hadas para referir el final abrupto de la inocencia como consecuencia del golpe de Estado: "Y fue entonces, cuando yo tenía dos años, que el cuento de hadas se acabó, no como se acaban los cuentos, con colorín colorado y campanitas, sino como se acaba un libro al que le han arrancado la mejor parte y el final" (p. 59).

De este modo, la literatura de la generación de los hijos de la dictadura de Pinochet conforma un espacio textual atravesado por obsesiones (vocación nostálgica), culpas (las heridas espectrales de la violencia estatal) y traumas (eventos históricos o naturales) que, agrupados en una constelación compuesta de fragmentos, captura los sueños y frustraciones almacenados de toda una época. En este sentido, si las novelas de esta generación de escritores expresan mediante un lenguaje "minimalista" (Rojo) el modo en que la incorporación interviene donde la introyección falla (el duelo incompleto), se debe a la obsesión narrativa por volcarse al pasado, por persistir en el trabajo de duelo, y por describir la "contraépica" (Rojo) de la "derrota" (Avelar) de una generación de chilenos.

En su estudio sobre la novela gótica, Christine Berthin (2010) explica la transmisión generacional de ciertas obsesiones no resueltas en relación con la noción de fantasma de Abraham y Torok:

For Abraham and Torok haunting is transgenerational. It takes the shape of a secret transmitted within a family or a community without being stated because it is associated with repressed guilt, shame or is the result of a trauma that has not been worked through. Because it remains unstated, the secret constitutes what Abraham calls a "phantom": an un- 
conscious formation which has never been conscious and is conveyed from a parent, a dead person or a lost object to the unconscious of the child, the living subject or "phantom carrier. (p. 4$)^{5}$

Basado en lo anterior, se puede afirmar que la narrativa de esta generación es "portadora fantasma" de una Historia que acecha obsesivamente a estos escritores. A fin de cuentas, una parte importante de la narrativa postdictatorial versa sobre la exclusión de un deseo consistente con el motivo literario de la pérdida de la inocencia, que en el caso de esta narrativa se relaciona con la figura de la recuperación de la inocencia perdida mediante el impulso nostálgico de la autoconciencia biográfica de los narradores. Además, no deja de representar una paradoja en el contexto del estudio de esta narrativa que uno de los motivos principales del género gótico corresponda a los secretos no declarados del pasado que "haunt younger generations and warp the course of their existence, live burials and ghosts that return on unfinished business" (Berthin, 2010, p. 5) ${ }^{6}$. Todo indica que es el evento histórico de la dictadura el muerto viviente o fantasma que retorna a esta literatura para atormentar a las nuevas generaciones con el objetivo de conmemorar mediante el trabajo de duelo la exclusión de un deseo: la recuperación de la inocencia.

En consecuencia, si hubiese que realizar una analogía criptológica de la narrativa chilena de postdictadura, la cripta constituiría en este contexto la estructura narrativa profunda que da sostén a estos relatos biográficos de la infancia durante la dictadura militar, y la encriptación o estructura narrativa superficial el proceso escritural de incorporación de la persistencia del trabajo de duelo.

\footnotetext{
5 "Para Abraham y Torok, el acecho es transgeneracional. Toma la forma de un secreto transmitido dentro de una familia o una comunidad sin ser declarado, porque está asociado con una culpa reprimida, vergüenza, o es el resultado de un trauma que no ha sido resuelto. Debido a que permanece sin ser declarado, el secreto constituye lo que Abraham llama un 'fantasma': una formación inconsciente que nunca ha sido consciente y se transmite desde un pariente, una persona muerta o un objeto perdido al inconsciente del niño, el sujeto vivo o 'portador fantasma”' (Traducción propia).

6 "atormentan a las generaciones más jóvenes y deforman el curso de sus existencias, sepulturas vivas y fantasmas que regresan por asuntos pendientes” (Traducción propia).
} 


\section{CONCLUSIONES}

Cristián Opazo (2009) vislumbra en un corpus de novelas chilenas de fines del siglo XX y principios del $\mathrm{XXI}^{7}$-aunque con objetivos distintos- algunas de las características asociadas a esta corriente melancólica o "estoica" (Álvarez) de la narrativa postdictatorial chilena. Para Opazo, el sujeto de enunciación de estas novelas corresponde a la figura del "hombre gris" que se resiste a los cambios del presente -globalización y transición a la democracia- mediante la "evocación" melancólica de la ciudad inmortalizada por los novelistas sociales (p. 93) ${ }^{8}$. Específicamente, la figura del hombre gris se estructura como un yo nostálgico que se resta del paisaje contemporáneo, con el fin de retrotraerse a una geografía urbana donde la "(enunciación volteada hacia la ensoñación de un pasado fenecido), aparece casi siempre transida por [la] culpa, la melancolía y el tono elegiaco" (p. 94). Más adelante, Opazo describe este tipo de novela ${ }^{9}$ como una escritura de los "hombres oscuros" que alegóricamente da cuenta del levantamiento del cuerpo cívico versus la novela de los "hombres grises" que cuentan su mutilación y ruina (p. 98). De este modo y ante un presente en ruinas, los hombres grises no tienen otra alternativa que hacer "de las citas al urbanismo y la[s] novela[s] sociales, un espacio afectivo donde capear la alienación y las condiciones de anomia generadas por el mesianismo neoliberal" (p. 99). En este contexto, vale preguntarse entonces: ¿cuáles son, al interior de esta genealogía, las características que les corresponderían a la generación de escritores hijos de la dictadura? En especial, si se toma en cuenta que el "stress it lays on childhood memories in the writer's life (...) is ultimately derived from the assumption that a piece of creative writing, like a day-dream, is a continuation of, and a substitute for, what was once the play of childhood" (Freud, 1989, p. 427 ${ }^{10}$.

En primer lugar, se puede observar una continuidad literaria entre la narrativa que Opazo estudia y la narrativa representada por Zambra, Fer-

\footnotetext{
${ }^{7}$ Mercenario ad-honorem (1991) de Gregory Cohen; La secreta guerra santa de Santiago de Chile (1989) de Marco Antonio de la Parra; El color de la piel (2003) de Ramón Díaz Eterovic; Machos tristes (1991) de Darío Oses; La patrulla de Stalingrado (1994) de Radomiro Spotorno y Poderes fácticos (2003) de Carlos Tromben.

${ }^{8}$ Llamada también literatura del realismo social. Véase la novela Los hombres oscuros (1939) de Nicomedes Guzmán.

${ }^{9}$ En un símil con la novela social escrita entre 1930 y 1940 que impugna los órdenes sociales clasistas y exalta las utopías frente-populistas de la época.

10 "el estrés que recae sobre los recuerdos infantiles en la vida del escritor (...) se deriva en última instancia de la suposición de que una obra de escritura creativa, como un sueño diurno, es una continuación y sustitución de lo que alguna vez fue un juego de infancia" (Traducción propia).
} 
nández y Sanhueza, entre otros. En segundo lugar, la evocación melancólica centrada en el mundo concreto de lo urbano de los novelistas sociales da paso en estas obras más contemporáneas a la "vocación nostálgica" de una atmósfera opresiva de la violencia. Es decir, no hay levantamiento ni mutilación del cuerpo cívico, sino una sorprendente voluntad obsesiva por revisitar el "pasado afectivo"reciente: los sueños, frustraciones y pesadillas almacenados por la memoria de la autoconciencia biográfica. En tercer lugar, el sujeto de la enunciación, la figura del hombre gris o del hombre oscuro que discute Opazo, se transforma en estas narrativas en la figura del hombre doliente: un yo nostálgico que no se resta del paisaje contemporáneo, al contrario, la misma participación en la contingencia del presente neoliberal globalizado le permite volcarse al período de la infancia de la dictadura militar de Pinochet. En cuarto lugar, a los hombres y mujeres dolientes no les queda otra alternativa, ante un presente neoliberal, que volver a la atmósfera afectiva de la infancia, donde los recuerdos del escritor derivan en escritura creativa (como una pesadilla diurna), que continúa las condiciones neoliberales del Chile actual. En definitiva, la persistencia de volcarse al pasado sustituye lo que era una vez un juego de la infancia por la persistencia del trabajo de duelo (las obsesiones fantasmagóricas de la infancia) y la pérdida de la inocencia: los desvíos obsesivos hacia el yo literario de la postdictadura.

\section{REFERENCIAS}

Abraham, N. y M. Torok (1994). The Shell and the Kernel: Renewals of Psychoanalysis. Chicago: Chicago UP.

Abraham, N. y M. Torok (2005). The Wolf Man's Magic Word: A Cryptonymy. Pról. Jacques Derrida. Trad. Barbara Johnson. Minneapolis: Minnesota UP.

Álvarez, I. (2012). Sujeto y mundo material en la narrativa chilena del noventa y el dos mil: estoicos, escépticos y epicúreos. Revista Chilena de Literatura 82, 7-32.

Amaro Castro, L. (2013). Formas de salir de casa, o cómo escapar del Ogro: relatos de filiación en la literatura chilena reciente. Literatura y Lingüística $29,109-129$.

Avelar, I. (2000). Alegorías de la derrota: la ficción postdictatorial y el trabajo de duelo. Santiago: Cuarto Propio.

Barraza Toledo, V. (2011). Alegorías de la posdictadura: trauma, lenguaje y memoria en la narrativa de Andrea Maturana. Anales de Literatura Chilena 15, 93-109.

Berthin, C. (2010). Gothic Haunting: Melancholy Crypts and Textual Ghosts. New York: Palgrave Macmillan. 
Bottinelli Wolleter, A. (2016). Narrar (en) la 'post': la escritura de Álvaro Bisama, Alejandra Costamagna, Alejandro Zambra. Revista Chilena de Literatura 92, 7-31.

Costamagna, A. (1996). En voz baja. Santiago: Lom.

Ferbert, E. (2013). Philosophy and Melancholy: Benjamin's Early ReflectionsonTheater and Language. Stanford: Standford UP.

Fernández, N. (2012). Fuenzalida. Santiago: Random House Mondadori.

Franken, M. (2017). Memorias e imaginarios de formación de los hijos en la narrativa chilena reciente. Revista Chilena de Literatura 96, 187-208.

Freud, S. (1967). Moses and Monotheism. Trad. Katherine Jones. New York: Vintage Books.

Freud, S. (1989). The Standard Edition of the Psychological Works of Sigmund Freud. Ed. James Strachey. New York: W.W. Norton \& Company.

Freud, S. (1992). Sigmund Freud. Obras Completas. Vol. 14 (1914-1916). Trad. José L. Etcheverry. Buenos Aires: Amorrortu editores.

Freud, S. (1995). The Freud Reader. Ed. Peter Gay. New York: W. W. Norton \& Company.

Guzmán, N. (1995). Los hombres oscuros. Santiago: Zig-Zag.

Hirsch, M. (1999). Projected Memory: Holocaust Photographs in Personal and Public Fantasy. En Mieke, B. (ed.) Acts of Memory: Cultural Recall in the Present (pp. 3-23). Hannover: New England UP.

Lyotard, Jean-François. (1984). The Postmodern Condition: A Report on Knowledge. Minneapolis: Minnesota UP.

Maturana, A. (1997). El daño. Santiago: Alfaguara.

Maturana, A. (2006). No decir. Santiago: Alfaguara.

Montes Capó, C. (2018). Imaginarios apocalípticos e infancia en las novelas En voz baja de Alejandra Costamagna y La edad del perro de Leonardo Sanhueza. Alpha 47, 279-289.

Moulian, T. (1997). Chile actual: anatomía de un mito. Santiago: Lom.

Opazo, C. (2009). Anatomía de los hombres grises: rescrituras de la novela social en el Chile de postdictadura. Acta Literaria 38, 91-109.

Richard, N. (1994). La insubordinación de los signos: cambio político, transformaciones culturales y poéticas de la crisis. Santiago: Cuarto Propio.

Richard, N. (2007). Fracturas de la memoria: arte y pensamiento crítico. Buenos Aires, Siglo XXI Editores.

Rojas, S. (2015). Profunda Superficie: memoria de lo cotidiano en la literatura chilena. Revista Chilena de Literatura 89, 231-256.

Rojo, G. (2016). Las novelas de la dictadura y la postdictadura chilena. Volumen I. ¿Qué y cómo leer? Santiago: Lom.

Sanhueza, L. (2014). La edad del perro. Santiago: Random House.

Zambra, A. (2011). Formas de volver a casa. Barcelona: Anagrama. 